\author{
V International Forum on Teacher Education
}

\title{
Some Aspects of Vocal Training of the Future Music Teacher in a Bilingual Environment through the Elements of Moodle
}

\author{
Nelya K. Nurgayanova*(a), Svetlana V. Karkina (b), Juanjo Mena (c) \\ (a), (b) Kazan Federal University, 420008, Kazan (Russia), 18 Kremlyovskaya street \\ (c) University of Salamanca, 37008, Salamanca (Spain), 15 Augusta street
}

\begin{abstract}
The study is relevant due to the need for the preservation of cultural traditions that include different peoples' identities. An important way is the use of ethnic vocal traditions which include the experience earlier generations in art, moral and aesthetic knowledge. Learning of the vocal basis in the traditional face-to-face and online format allows to offer available content, a better update of the logically organized subject. Also, it provided connected knowledge learning that tends to build new ideas on the basis of traditional culture through collaboration.

The purpose of the paper is to study the usage of national vocal traditions in the learning process of future music teacher through the elements of Moodle, such as lectures about vocal art and assessment resources.

The research used the following methods: analysis of musical-pedagogical literature, studying educational documents, analysis of national vocal traditions, questioning, testing, interviewing.

The results of the complex educational process include traditional face-to-face and digital format that show a deep understanding of students' intonation system of folk melodies and features of traditional musical culture.

The researchers concluded that the main role of the folk vocal performance traditions in the process of improvement of professional knowledge and skills of the future music teacher include their emotional state, moral, aesthetic and spiritual qualities.

These results will allow increasing the quality of the process of professional creative realization of the future music teacher through the interaction to the vocal art of different peoples by smooth communication at the Moodle environment.
\end{abstract}

Keywords: music teacher; distance learning; ethnic culture; music folklore; folk singing.

(C) 2019 Nelya K. Nurgayanova, Svetlana V. Karkina, Juanjo Mena

This is an open access article distributed under the terms of the Creative Commons Attribution License (CC BY 4.0), which permits unrestricted use, distribution, and reproduction in any medium, provided the original author and source are credited.

Published by Kazan federal university and peer-reviewed under responsibility of IFTE-2019 (V International Forum on Teacher Education) 


\section{Introduction}

The study is significant because of the need to preserve cultural traditions that include different peoples' identities. An important way is the use of ethnic vocal traditions which include the experience of earlier generations in art, moral, and aesthetic knowledge. One of the important elements in the process of preparing future music teachers for professional activity in a bilingual environment is the use of the pedagogical potential of the regional ethnic musical traditions. Through the theoretical and practical development of the main genres and laws of traditional musical art, there is an education of interest and respect for folklore as a national and world heritage.

Nowadays, the dialogue about effectiveness in the educational process of the online format is intensive. The use of distance learning became very popular and the number of online-learning platforms increases. The learning of the vocal basis in the traditional face-to-face and online formats allows offering available content, a better update of the subject. Also, it provides the connected knowledge learning that tends to build new ideas on the basis of the traditional culture through collaboration.

\section{Purpose and objectives of the study}

The purpose of the paper is to study the use of national vocal traditions in the learning process of future music teacher through the elements of Moodle such as lectures about vocal art and assessment resources.

\section{Literature review}

Practical experience of teaching singing shows that the most accessible material for the development of vocal skills is folk songs. Their intonation system, special melodic turns, narrow range, and melodiousness contribute to the development of cantilena, natural sound production, evenness of voice, free and easy manner of performance. This is evidenced by the existing body of research and vocalmethodical developments by Almeeva (2009), Daleckij (1976), Nurgayanova (2015), Shamina (1997), Shastina (2010), Shashkina (2014).

Thus, Daleckij (1976) in his work shows that folk tunes are very convenient for singing as they meet the characteristic features of the human voice. The researcher, having studied a large number of samples of folk songs that differ in genres, musical characteristics, local traditions, determined the average range of songs, which is quite constant, convenient for unprocessed voices. The scientist comes to the conclusion that it is in the folk song that the general properties and possibilities of the singing voice are reflected since for many centuries it has been performed by voices similar in their basic physiological properties. In the process of transition from generation to generation through the voice apparatus of a huge number of untrained singers, folk song as it is polished, inevitably losing vocal inconvenience, sweeping away everything that contradicts the natural nature of the voice (Daleckij, 1976).

According to Shamina (1997), the formation of the culture of singing sound regardless of the manner of singing should correspond to the existing aesthetic ideal of vocal art. Therefore, the training of singing should begin with the development of vocal skills, consisting in the development of the laws of the function of voice formation: breathing, high singing position, rounding sound, uniform manner of sound formation over the entire range of voice, mobility of articulation apparatus, flow and purity of vowel pronunciation, milling, soft attack as the main method of 'entering' into the sound, smooth, cantilena sound (Shamina, 1997).

Shastina (2010) connects singing traditions with the concept of 'vocal ethnopedagogics', points 
out the importance of students' acquaintance with the local singing culture of different regions. She defines this term as an educational and teaching system without writing, including a set of ideas, views on the education of singing culture and has its own didactics, which has an involuntary influence on a person (Shastina, 2010).

The development of multimedia resources has allowed new ways in music education. The use of Massive Open Online Courses is an example of a new model of distance education (Ramirez-Montoya, Mena, \& Rodriguez-Arroyo, 2017) that allow the implementation of modern pedagogic approaches. The majority of research on distance learning was conducted on the use of Moodle education (RamirezMontoya, Mena, \& Rodriguez-Arroyo, 2017) and focused on the problem of the quality in virtual education environments (Barbera, 2004) where they have highlighted the main reasons for support of the combination of e-learning and face-to-face teaching are accessibility, flexibility, and interactivity (Rosenberg, 2001). Analysis of researches allowed to state that music distance learning is important for providing quality musical instructions, eliminating various barriers such as socio-economic status or geographical location, offering deeply reflection by instructors of teaching process (Pike, 2017). Moodle tool allows using distance format in a most appropriate way such as connected knowledge for building 'ideas on the basis of others through collaboration' (Olmos, Mena, Torrecilla, \& Iglesias, 2015).

\section{Methodology}

The research based on the methods: analysis of musical-pedagogical literature, studying of the educational documents, analysis of national vocal traditions, questioning, testing, interviewing. The special content was put in the distance learning format in Moodle environment include the lectures about vocal art and assessment resources.

The experimental base of the research was the Kazan (Volga region) Federal University.

The research was conducted at three stages. At the first stage, the analysis of the existing musicalpedagogical, vocal-methodical literature was carried out, the pedagogical analysis of singing traditions were carried out; the problem, the purpose, methods were singled out, the plan of research was made. At the second stage, the development of teaching materials, manuals, special courses, electronic educational resources was carried out. At the third stage, the implementation of the developed materials in the process of vocal training of the future music teacher in a bilingual environment using MOODLE elements was carried out.

\section{Results}

The results of the complex educational process include traditional face-to-face and digital format, i.e. the deep understanding of students' intonation systems of folk melodies and features of traditional musical culture.

On the basis of the pedagogical analysis of singing traditions, the use of methodological principles of pedagogical potential of folk songs, which are reflected in scientific works, music collections, anthologies, textbooks published in different years, was developed, published and implemented in a remote format as an educational manual 'Vocalizes based on the melodies of the peoples of the Volga region' (Nurgayanova, 2015).

This methodological development allows including in the educational repertoire of the future music teacher songs of indigenous ethnic groups of the Middle Volga region - Tatars, Russians, Chuvash, Mari, Mordvins, Udmurts, using them as vocalizes. Singing traditions of different peoples of the Volga 
region are distinctive and unique but at the same time, the musical system of each ethnic group contains a lot of universally important features coming from the universal aesthetic categories of auditory perception and musical thinking as well as similar conditions of historical, social, economic development in a single territorial space. An important aspect of this manual is that it is one of the forms of acquaintance with the ethnic culture of the Middle Volga region. This allows students, unfamiliar with the singing traditions of the region, an opportunity to understand the intonation system and learn some of the features of folk music of the Volga ethnic groups. On the other hand, for students brought up on traditional melos, these vocalizes can become a transitional stage to the development of intonation and harmonic properties of classical and modern vocal music.

Presented in the collection of musical material aimed at the conscious mastery of different types of vocalization, elements of vocal technique, allows to work on the development of such singing skills as proper voice formation, smooth voice, cantilena, clear diction, sound support, which will undoubtedly contribute to the successful solution of vocal problems in the process of voice production.

The content of the training manual includes twenty-five musical examples of vocalizes accompanied by a piano, with each number corresponds to the guidelines and recommendations to teachers and students, also provides a list of special literature and information resources, given the lyrics. Piano accompaniment is written in a lightweight version, which allows students to work on their own vocalizes.

Vocals № 1 is written on the basis of Chuvash folk songs «Alran kajmi aki-sukhi» - « Song of the plow». The singing lingering melody, sounding at a slow pace, includes long intervals and requires a wide singing breath, good sound support. A particular difficulty is the variable size of the song, characteristic of Chuvash folk music with alternating even and odd rhythm on the bars. Vocalization is intended for all types of voices to strengthen the middle register of the range, it is recommended to perform with the names of notes.

Chuvash folk song was also used when writing the vocals № 2 («An avan, sheshke» - « Don't bend, hazel»), № 6 («Ves, ves, kukkuk» - « Fly, fly, cuckoo») and № 10 («Kaj, kaj, Ivana!» - «Marry, marry Ivan!).

Ethno-musical culture of the Mordovian people is represented by the song P. Gajni «Asho lov» «White snow» (Vocals № 3) and by the folk song «Luganjasa kelunje» - «In the meadow birch» (Vocals № 13).

The song folklore of the Volga Tatars is reflected in the samples of vocalises № 4 («Borlegan» «Stone berry»), № 7 («Dulkyn» - «Wave»), № 12 («Kuk-kugerchen» - «Blue dove»), № 15 («Ommegelsem»), № 16 («Sandugach-kugerchen» - «Nightingale-dove»), № 17 («Su bujlap» - «Along the river»), № 18 («Tugan ilkaem» - «Homesickness»), № 19 («Tugan tel» - «Native language»), № 20 («Urmannarda jordem» - «Walking in the woods»), № 22 («Urakchy kyz» - «Girl-reaper»).

For example, mobile melody of the Tatar dance songs «Ommegelsem» (Female name) is used in the vocals № 15. This example is convenient for working on a high position of the singing sound, strengthening the middle voice register. When performing, it is necessary to monitor the smooth sound of repeated notes $\mathrm{d} 2$ and $\mathrm{h} 1$. It is advisable to sing with the names of the notes to produce a good diction.

Mari folk songs formed the basis of vocalizes № 8 («Izi chodyrat» - « Small forest »), № 9 («Jyldyr-jyldyr» - «By the stream ») and № 24 («Jandar jukan kukuzho» - «Where the cuckoo cuckoo»).

Udmurt folk songs formed the basis of the vocals № 14. («Lymy tedi» - wedding song «White snow»), № 25 (Udmurt dance tune «Jalyke» - call: «Let's dance!»). For the vocalis № 23 used the melody of the Udmurt lullabies «Chagyr, chagyr, dydyke» («Blue, blue, dove»). Vocalization is designed to work 
on the singing breath, clarity of pronunciation, expressiveness of performance. Large melodic leaps require good support, the attack of sound 'without entrances'.

A special place in the manual is given to Russian folk songs which are widely used in vocal and pedagogical practices. These are well-known songs «In the field birch stood» (Vocalis № 5), «Kalinka» (Vocalis № 11) and «At Zorya» (Vocalis № 21).

The musical example 4 presents a vocalization based on the song «Birch stood in the field», the melody of which with repeated sounds on the descending steps is a vocal convenience for voice production at the initial stage of training.

The presented vocalizes were tested in the process of implementing the disciplines of solo vocal and performing training of students studying the module «Pedagogical education», the profile of training «Music and additional education in a bilingual environment» within the educational process of the Institute of Philology and intercultural communication of the Kazan (Volga) Federal University. For this purpose, the special resource based on Moodle environment was created. During the research work, each student learnt in the traditional way based on face-to-face interaction and through the distance course at home by the personal computer. The process included reading lectures and additional materials, viewing musical illustrations, implementation of self-assessment exercises for the control of learning. That way allowed students to learn the musical and theoretical material during as much time as they needed.

At the distance resource, they read about different folk traditions. This way allowed students to get knowledge in a connected way and create new ideas through collaboration with other researches. It was necessary for a better understanding of the musical meaning of vocalizes. Then, they did interactive tasks for art analysis of theoretical material and musical examples. Interaction with the teacher took place through comments to the answers and assessments. Also, interaction with other students took place by resources forums and chats where students talked to each other about new material and principles of its analysis.

During the study process, students listened to these vocalizes in a good performance and learnt the melodies on the distance resource. Some of the students did not know the names of musical notes very well. That is why they needed more time for learning and special tools for doing it. In distance environment, they used a special e-musical program Sibelius for learning note names in a practical way. Also, this way was very useful because the majority of the students did not have a piano in their homes and this way was the priority for self-learning. The use of a distance learning environment allows students to get teachers instructions all the time that they need and to have a lot of practice for themselves.

\section{Discussions}

In the conditions of the multinational Russian state, the focus of education on the formation of a person capable of living in a multicultural environment that respects other people's traditions and other cultures becomes particularly relevant. This requires improvement of the educational process and fundamentally new approaches to improving the quality of training of students - future teachers who are aware of their high importance in introducing the younger generation to the spiritual, moral, aesthetic values not only of their own but also of other ethnic groups.

In the process of formation of the ability to intercultural and interethnic interaction, its unique role is designed to perform music teacher as a carrier of cultural traditions and a specialist in the field of musical and aesthetic education of children. A distinctive feature of the profession of teacher-musician is the structure of its activities, including both pedagogical and musical-performing component. 
The analysis of the current practice of teaching music teachers showed that the process of vocal and performing training is mainly aimed at the development of technical qualities and narrow-specific skills. At the same time, in the forthcoming professional, cultural and educational activities of the future specialist, the pedagogical potential of the disciplines of the musical and performing cycle is not used as much. First of all, it concerns the pedagogical potential of ethnic singing traditions, on the basis of which, as a result of the transfer from generation to generation of artistic and aesthetic experience, the development of the musical culture of the past took place. Numerous studies show that stable centuries-old traditions, performing the function of systematization of ethnic cultural spiritual values, determined the specific characteristics of the social structure, moral and aesthetic consciousness, causing both distinctive and universal features. Song folklore, which is an important factor in the education and equipment of information about the world of the younger generation, has always occupied a significant place in the extensive structure of folk traditions.

The pedagogical aspect of training in traditional singing drew attention of ethnomusicology Almeeva (2009), pointing to the mandatory presence in the process of familiarizing with the origins of ethnic culture 'ethnographic, cultural background', designed to "awaken the genetic memory of children, students, to feed their morality and spirituality" (Almeeva, 2009, p. 311). Consequently, the introduction of the younger generation to the origins of traditional singing culture forms the ability of the individual to the ethnic cultural identification.

In our opinion, the solution to the pedagogical problem of the development of singing traditions of different peoples can contribute to the actualization of the following research tasks:

- disclosure of artistic, moral, aesthetic and pedagogical potential of singing traditions of different ethnic groups in the process of their development and intercultural interaction;

- theoretical analysis of traditional song folklore with identification of characteristic genre and style features, poetic and musical content, place in the system of ritual, the historical origin of folk tunes for use in performing and pedagogical practice;

- the definition of ethnic and regional specifics of authentic folk music combined with materials that reflect the context of the existence of this folk system, features singing, compositional structure in the field of metro-rhythmic, lade-international organizations, monody or polyphony;

- definition of forms of application of ethnic singing traditions in modern musical and pedagogical education, creation of teaching aids from the works of folk vocal creativity and guidelines for the development of educational and concert repertoire based on folk tunes.

The use of distance learning became very popular in modern times. There are a lot of platforms such as Coursera, UdX, Udacity that are offer courses for learning every school subject for different purposes. The emerging issue is a possibility of improvement of music performance skills through online education. Leading world universities offer distance courses based on Coursera for teaching a wide range of performance skills: vocal, playing musical instruments, public speaking, dancing. There is even a course for learning improvisation that is the most difficult musical discipline for training performance skills. According to a research opinion, the online format has some advantage in comparison with traditional learning: unlimited resource for discipline content; timeless effective students practice.

These advantages provide getting the discipline content without any frameworks and allowing students as much time as they need. This approach allows learning the content carefully and getting deep meanings. Another advantage of the online format is the opportunity for performing student's piano practice in a most comfortable way. In some cases, without teacher interaction, students can get a way for a 
personal approach for improvement of the performing skills.

\section{Conclusion}

The result of comprehensive training, combining traditional and digital formats, was a deep understanding of students' intonation system of folk melodies and features of traditional musical culture.

According to the results of the study, it was concluded that the combination of traditional and online education contains a great pedagogical potential and contributes to the effectiveness of the study of folk singing traditions in the formation of the readiness of the future music teacher to professional activity in a bilingual environment. The potential of traditional and distance learning is as follows:

- the main role of the folk vocal performance traditions in the process of improvement of professional knowledge and skills of the future music teacher include their emotional state, moral, aesthetic and spiritual qualities;

- the possibility of the professional-creative realization of the future music teacher through the interaction to the vocal art of different peoples, folk vocal genres, intonation influence on the listeners in the process of smooth communication by means of the Moodle format.

The great popularity of the Internet throughout the world determines the most comfortable ways for learning without any frameworks such as time limits, geographical location or socio-economic status. It allows finding more ways for the educational process and might be a useful tool in the field of improvement of the musical performance skills.

In conclusion, it should be noted that working on the improvement of the vocal technique, the development of the vocal skills, it is necessary to strive for the main goal of training which is the formation of artistic and aesthetic taste, the disclosure of the creative potential of the individual.

\section{Acknowledgments}

The work is performed according to the Russian Government Program of Competitive Growth of Kazan Federal University.

\section{References}

Almeeva, N. J. (2009). Tatarskij pesennyj fol'klor: problemy vhozhdeniya v tradicionnoe ispolnitel'stvo [Tatar song folklore: problems of entering traditional performance]. High and school musical education, 307-321.

Barbera, L. (2004). Quality in virtual education environments. British Journal of Educational Technology, $35(1), 13-20$.

Daleckij, O. V. (1976). Ob ocenke vokal'nosti melodicheskogo materiala na osnove rezul'tatov analiza narodnyh pesen [On the evaluation of vocal melodic material based on the results of the analysis of folk songs]. Issues of vocal pedagogy, 231-236.

Nurgayanova, N. K. (2015). Vokalizy na osnove melodij narodov Povolzh'ya [Vocalise based on the melodies of the peoples of the Volga region]. Kazan: Izdatelstvo Kazanskogo universiteta.

Olmos, S., Mena, J., Torrecilla, E., \& Iglesias, A. (2015). Improving graduate students' learning through the use of Moodle. Educational Research and Reviews, 10(5), 604-614.

Pike, P. D. (2017). Improving music teaching and learning through online service: A case study of a synchronous online teaching internship. International Journal of Music Education, 35(1), 107117. 
Ramirez-Montoya, M. S., Mena, J., \& Rodriguez-Arroyo, J. A. (2017). In-service teachers` selfperceptions of digital competence and OER use as determined by a xMOOC training course. Computers in Human Behavior, 77, 356-364.

Rosenberg, M. (2001). E-learning strategies for delivering knowledge in the digital age. Columbus: McGraw-Hill.

Shamina, L. V. (1997). Shkola russkogo narodnogo peniya [School of Russian folk singing]. Moscow: Smysl.

Shastina, T. V. (2010). Osnovy obucheniya detej narodnomu peniyu sredstvami tradicionnoj pevcheskoj kul'tury [Fundamentals of teaching children how to sing using traditional singing culture]. International journal of experimental education, 12, 18-19.

Shashkina, L. A. (2014). Vokal`naya tekhnologija obuchenija narodnomu peniju detej i junoshestva v sisteme narodno-pevcheskogo obrazovanija [Vocal technology of teaching national singing of children and youth in the system of national singing education]. Vocal and choral upbringing of children and youth in the system of special and additional national singing education, 97-105. 